\title{
Granule for Suspension for Injection Dosage Form
}

National Cancer Institute

\section{Source}

National Cancer Institute. Granule for Suspension for Injection Dosage Form. NCI

Thesaurus. Code C149552.

Solid sterile preparation consisting of granules intended to be dispersed in the specified liquid to obtain a suspension for injection. 